\title{
CORRECTION IN HISTORICAL PERSPECTIVE
}

\author{
Thorsten SELLIN*
}

I

INTRODUCTION

A study of the changes that have occurred in our ideas of how to deal with offenders against the criminal law brings us into contact with one of the most fascinating and challenging aspects of social history, the history of punishment. It is, by and large, a sordid history; a record of our slow progress in finding effective means of reducing criminality by punishment; a record of much violence, brutality, torture, and indifference to human suffering, but also of charity, compassion, and honest search for methods of correctional treatment that will salvage rather than destroy those who are its objects. It is the purpose of this paper to attempt to disengage a few of the general trends that are discernible in that record and lay bare some of the conspicuous elements that compose these trends, especially since the Middle Ages.

To the casual student of the history of punishment and of the reasons given for its existence, character, and myriad forms, it would appear that there are two noticeable purposes of punishment and that while they are different in kind, they are not always completely separable. One of these purposes is the protection and conservation of the social interests or values which have been injured by the offender. It is a mundane purpose, nowadays often designated, especially abroad, by the term of social defense. This protection is thought to be achievable by various means, such as (a) the extermination of the offender; (b) making him so fear punishment that he will commit no more crimes (deterrence); or (c) reforming, re-educating, or curing him by more positive methods. The second purpose is other-worldly, so to speak. It views punishment as being inflicted in order to save the offender's soul, this end being achieved by his repentance and atonement.

Next, we must consider the human motives, wishes, and desires that have led us to establish and apply punishments that would effect the means and thereby achieve the purposes or ends thereof. Prominent among these motive forces have been (a) a primitive desire for vengeance or retaliation; (b) compassion with sinners

*A.B. 1915, LL.D. 1942, Augustana College; A.M. 1916, Ph.D. I922, University of Pennsylvania. Professor of Sociology, University of Pennsylvania. Member and Consultant, American Law Institute, Advisory Committees on the Youth Correction Authority Act and the Model Penal Code; Chairman, Governor's Commission on Penal and Correctional Affairs, State of Pennsylvania; Chairman, Board of Trustees, City Prisons, Philadelphia, Pennsylvania. Secretary-General, International Penal and Penitentiary Commission, I950-5I; Consultant, Swedish Penal Code Commission, 1946-47. Author, A Bibliographical Manual for the Student of Criminology (1935), Research Memorandum on Crime in the Depression (1937), Culture Conflict and Crime (1938), The Criminality of Youth (r940), PioneerING IN PENoLOGY (1944), and numerous monographs, pamphlets, and articles on various criminological and penological topics. 
or unfortunate fellowmen; (c) a wish to exploit the offender's productive capacities; and (d) the hope to turn him into a law-abiding citizen by some kind of rational treatment or therapy.

Even though a case could be made for the claim that these purposes, means, and motives have always existed in the civilized world, history suggests that their respective shares in the scheme of things have not at all times been of equal proportions. Although there have been times and places when the salvation of the soul of the criminal may have appeared to be the main aim of punishment, the "protection of society" has usually been the dominant purpose, the more so as man has proceeded to exchange his fear of the unknown for a confidence in his ability to penetrate it. As for means and motives, their interplay and the roles of their constituent parts have undergone great changes in the course of time. Indeed, the story of the changes in social attitudes toward the offender is essentially the story of how the roles of the various means and motives of punishments have progressively lost or gained in importance.

And that story is inextricably interwoven with the history of cultural change in general; for the nature of punishments and the motives behind them reflect the fundamental character of the structure, the institutions, and the intellectual life of society;.as these change, so do attitudes toward offenders, as well as the resultant ways of dealing with them. In surveying these last-mentioned changes, we shall examine separately (a) the retaliatory, (b) the exploitative, (c) the humanitarian, and (d) the re-educational-therapeutic elements in punishment. It is hoped that this examination will reveal something of the interrelationships and relative strength of these elements at different periods. The history we are studying is not like a ladder, on which each rung marks a clear division between one stage and the one above. It is more like a river, arising from several tributaries, some of which, owing to the operation of changing climatic factors, tend to grow more powerful, while others show signs of drying up; yet, all are adding their respective flow to the main stream.

II

\section{The Retaliatory Elemient}

No punishments illustrate the retaliatory element better than do capital and corporal penalties. The supreme penalty of death may well be the oldest of all punishments. In historical times, the manner of inflicting it has taken all conceivable forms, some of them designed to snuff out life speedily, others planned so as to prolong the agony of the victim as much as possible. The executioner's sword and the hangman's rope have been reasonably rapid methods, but those who have been burned at the stake, boiled or buried alive, broken on the wheel, or immured have known the full meaning of public vengeance and retaliation.

However, this penalty has undergone great changes in the last few hundred years and especially during the last century and a half. Where it was once employed 
in the case of all serious crimes in all nations, it has gradually become limited to. very few crimes or has been abolished altogether.

Statistical data on the relative use of the death penalty in early times are rare, especially long-time series which indicate trends. A most interesting series of this kind, and the longest reliable one so far produced, unfortunately applies to only one community, the town of Malines in Belgium. It covers five centuries before the French Revolution and, therefore, antedates the more recent abolitionist trend. During these centuries, Malines had a population that remained rather constant in. size, and the criminal law which it administered underwent no radical changes. Nevertheless, the annual average number of executions dropped from four during I370-I400, to two during the sixteenth century, to one every four years during the eighteenth century. ${ }^{1}$ There are good reasons for believing that this phenomenon was. no isolated one, but was occurring in the rest of Europe.

It has been estimated that during the 150 years beginning with the reign of Henry VIII in England and ending with the Commonwealth, the annual average of 300 executions at Tyburn (London and Middlesex) during the first half century dropped to ninety during the last thirty-five years. A century later, during the five decades. I749-98, the annual average number of criminals executed in London and Middlesex each decade ran to thirty-one, twenty-one, thirty-six, fifty-three, and twenty-one, respectively. Most of the executions were for crimes against property. ${ }^{2}$

A growing sentiment against the death penalty manifested itself during the latter half of the eighteenth century. The philosophers of the Enlightenment gave it voice. Becarria's essay On Crimes and Punishments ( 1764 ) was not the first to advocate the removal of this penalty, but it was written at a time when the soil was ready to receive the seed it planted. It took several decades for its influence to be fully felt. During the nineteenth century, however, the death penalty was abolished in many countries or otherwise reduced in scope. This general trend has continued to the present day, in spite of local and temporary reversals, until we must conclude that what was once a highly acceptable method of dealing with criminals has become archaic in our Western culture and a vestigial organ in our body politic.

Today, the death penalty has survived in Western Europe only in the British Isles, France, and Spain. The largest and most populous states of Central and South America have abandoned it. Canada still retains it, but in the United States, it is not found in seven states and has fallen into disuse in several others. What has happened in the United States illustrates the trend of events. First of all, there has been a general tendency to reduce the number of crimes punishable by death, at least if we compare the situation today with that of a century ago. Where formerly the death penalty was mandatory in case of conviction and was so still in a dozen states at the end of the first World War, the mandatory provisions have now disappeared from all states, at least in the case of murder, and judge or jury

${ }^{1}$ Maes, La peine de mort dans le droit crimizel de Malines, 28 Revue historiQue DE DROIT FRANCAIS ET ÉTRANGER 372,383 (4th ser. I950).

${ }^{2}$ I Leon Radzinowicz, A History of Evglish Criminal Law y42, i47 (1948). 
has been given the power to choose between the death penalty and some other punishment, usually life imprisonment. Executions have been made private, where formerly they were public, and this trend has been greatly accelerated by changing the method from hanging to electrocution or the gas chamber, which require more permanent installations. The traditional gallows, so characteristic of Anglo-American justice, have almost disappeared from the United States, owing to the belief that the other methods just mentioned are more "humane." Finally, a few states have altogether done away with the death penalty. Michigan was the first to do so, in 1846, followed a few years later by Maine. By rgoo, six states were in the abolitionist ranks. A strong movement in a considerable number of states about the time of the first World War increased the number' to twelve in 19r8; but two years later, there were but eight left; and by 1937, the figure had, again, gone down to six.

In 1958 , Delaware abolished the death penalty, the first state to do so in more than three decades. Sentiment for the removal of this punishment has again been growing, and there are many signs to indicate that some of our largest states are likely to follow Delaware's lead in the next few years. Such signs are apparent in California, New York, Illinois, and Massachusetts, for instance. Perhaps this is less surprising when we recall that the number of capital executions in our country has declined from over $15^{\circ}$ a year in the early part of the 1930's to sixty-five in 1957. Similar trends are noticeable both in France and in England. The simple fact seems to be that the death penalty has become incompatible with other ideas of how to deal with offenders. ${ }^{3}$

What has been said about the death penalty is even more true of corporal punishments. Since imprisonment was an uncommon form of punishment prior to the eighteenth century, corporal punishments ranked next to the capital ones in importance. Branding, mutilation, and flogging were frequently in use. Only flogging has survived here and there in our Western culture. The whip did not disappear from British law until 1948 , and it is still a legal form of punishment in Canada and some other Commonwealth countries, such as the Union of South Africa and Ceylon. Mutilation is still practiced in some parts of the Moslem world. In the United States, the traditional forms survived in several northern states until the early decades of the last century and in the South until some time after the Civil War. Delaware still retains the whipping post, but uses it only rarely nowadays. Indeed, that is something of an anachronism considering the step recently taken by Delaware to abolish the death penalty.

The retaliatory element is, of course, present in greater or lesser degree in other than capital or corporal punishments. It is present whenever the punishment inflicts suffering without regard to the offender's future rehabilitation, and it is clearly reflected in the vicious sentences to long prison terms that tend to be demanded and imposed when public sentiments have been aroused by some brutal crimes.

${ }^{3}$ For a more detailed discussion of the death penalty, its history, extent, rationale, and effectiveness, here and abroad, see the symposium, Murder and the Penalty of Death, 284 Annals (1952). 
III

The Exploitative Element

Those who today complain that our prisons are great financial burdens on the taxpayer might well be surprised to learn that the use of prisons in connection with punishments developed for the purpose of exploiting the manpower of criminals and making them financially profitable. The use of criminals to build roads, fortifications, and public works goes back to ancient times. In ancient Rome, criminals were sometimes sent to labor in the mines and quarries. Mining continued, in many countries, to be a favorite way of exploiting criminals, partly because of the hazards such labor involved, and it is a curious fact that the first state prison in the United States-in Connecticut-was in a mine. Whatever might have been the form of exploitation, it is obvious that when such criminals were not engaged in work, they had to remain confined somewhere if they were to be counted on to complete their tasks; hence, the need for prisons that were mere places for the safekeeping of these unwilling laborers.

Perhaps the best illustration of penal servitude is the system of galley slavery which was introduced toward the end of the Middle Ages in the countries bordering on the Mediterranean Sea. The practice seems to have begun in France shortly before the middle of the fifteenth century and spread from there to nearby maritime countries. Gradually, many criminals who would otherwise have been sentenced to death or corporal punishments were committed to the galleys, warships peculiarly suited to the Mediterranean and propelled by rowers.

Numerous other illustrations could be given. The first state prisons in the United States were set up as institutions for the confinement of criminals sentenced to perform hard labor, and until relatively recent times, and still in some states, one of the chief elements of punishment has remained the financial exploitation of the prisoner's manpower. We need only mention the lease system of prison labor, which was not completely abolished until thirty-five years ago, and the system of contract labor for the benefit of private employers, which remained in many states until twenty-five years ago. The chain gangs are still remembered, and there can be little doubt that in many places, the improvements in living conditions in prison road camps has in part been motivated more by a need for maintaining healthy work crews than by a desire to rehabilitate offenders.

\section{IV}

\section{The Humanitarian Element}

Humanitarian sentiments and feelings have played a large role in the transformation of punishments, especially since the beginning of the Christian era, for these feelings are closely bound up with religious beliefs. Charitable agencies, societies, etc., developed quite early for the purpose of bringing solace in some form to poor 
prisoners, visiting them, ransoming them, and burying them. All the early prison reformers were motivated by Christian charity and compassion, and these sentiments played a large role in the movement to reduce the use of corporal and capital punishments, improve conditions in jails, and lighten the burdens of imprisonment. The first programs of education of prisoners aimed to teach them to read religious books, and the first prison libraries were chiefly stocked with devotional literature. Humanitarian sentiments were largely responsible for the introduction of medical services to prisoners. The first prison society in the United States was formed to "alleviate the miseries of public prisons." Indeed, until recent times, penal reform has been to a large extent dictated not by a carefully studied plan to develop effective penal treatment, but by humanitarian sentiments.

\section{V}

\section{The Treatment Element}

The greatest changes in our attitudes toward the offender have occurred during the last two centuries. They are attributable to two great movements which can be roughly traced back to ideas that reached fruition or were being foreshadowed in the late eighteenth century-the rise of a philosophy of democracy and the birth of the behavioral sciences. The former led to great political upheavals, and the latter produced a revolution in our views regarding the nature of the offender and his treatment.

The rationalists of the eighteenth century were convinced that research would be able to uncover not only the scientific laws that governed the inanimate world, but the laws that ruled social life and the behavior of man. The fumbling efforts to understand human behavior by physiognomics that culminated in the work of Lavater became more systematic in the researches of Gall, the father of "phrenology," whose ideas are no longer acceptable, but who fully understood their implications for penology. The leading brain anatomist of his age, Gall became convinced that the explanation of all human behavior was to be found in the structure of the brain; his studies of criminals confirmed him in that belief. It is not very important that his theories could not be substantiated, but it is important that they caused him to stress the need for the individualization of punishment. He regarded it as axiomatic that punishment should be fitted not only to the crime, but to the criminal as well, just as physicians who have diagnosed a disease must consider the nature of the patient when prescribing treatment.

In the demand for individualization of punishment, he received ample support from the infant science of psychiatry. Not long after the American Revolution, Benjamin Rush had studied what he called the diseases of the moral faculty. What he called anomia developed later in the clinical studies of Pinel, Esquirol, and Pritchard into what came to be known as moral insanity, a conception of the cause 
of crime which definitely placed the criminal into the category of the mentally diseased and hence in need for preventive care rather than punishment.

There is no need to describe here in any great detail the variety of researches or theories about the causation of crime which flourished during the last century nor their successors during the present century. Suffice it to say that whether we consider the individualistic theories of the criminal anthropologists, the hereditarians, the psychoanalysts, or the psychologists or the environmental theories of the positivists, the Marxians, the sociologists, and others, they all pointed in the same direction so far as the penal system was concerned; they all demanded that punishment be fitted to the punished and not to the crime, broadly speaking. To the investigators of the matrix and phenomena of human behavior, criminals were not all alike and should not be treated as if they were. The fact that two persons had committed the same crime was not, to them, a sound reason for giving them the same punishment. And as scientists, they easily arrived at the conclusion that the criminal should not be sentenced to a fixed and unalterable punishment, but that his correctional treatment should have flexibility if it were to meet society's demand for protection against him and to serve best his need for effective therapy.

It is obvious, that whatever humanitarian sentiments may have lurked in the recesses of the minds of those who called for a scientific basis for the treatment of the offender, this basis was not that of the humanitarians, nor of the retaliators or the exploiters. And who would question the enormous influence that the scientific movement has had on our penal system? We need only to look at the innovations of the last century to see how different the correctional system of a modern state is as compared with that of earlier days. At the beginning of the nineteenth century, fines, one or two forms of imprisonment, the death penalty, and perhaps the lash were the usual punishments; today, a variety of specialized institutions, probation, indeterminate sentences, parole, juvenile courts, etc., testify to the impact which the behavioral sciences have had on our legislation. The concept of individualized treatment has received general acceptance-within limits which may be modifiable but certainly not removable during the foreseeable future.

The mention of these limits brings us back to the democratic movement. We are told by the legal historian that justice was marked by great arbitrariness prior to the nineteenth century, at least on the continent of Europe, and that it favored the ruling classes. The egalitarian political philosophy which matured during the eighteenth century brought significant changes. Even before Beccaria published his famous essay, Voltaire had called for the abolition of arbitrary punishments. Judges, he claimed should act on the basis of well-formulated laws, so that citizens would no longer have to complain of arbitrary justice and judges would not have to fear the hatred of the people, since punishments would be dictated by law and not by the sentiments of the judge. ${ }^{4}$

- François Marie Arouet de Voltaire, idées républicaines xl (i762). 
Beccaria clarified the issue still further. Criminal law should be based, he said, on the concept of the equality of men. Definite punishments should be fixed by laws adopted by representatives of a political society based on the social contract. Courts should determine the guilt of the accused, but should not be allowed to interpret the law, since nothing would be more dangerous than to judge in accord with the "spirit of the law," for in that case, this spirit would depend on the judge's good or bad logic, his good or bad digestion, the strength of his emotions, or the frailties of the accused. The same judge might even, at times, impose different punishments for the same crime! There might be some inconveniences in the literal application of the law, but the legislature could always change it. Otherwise, the accused would become the slave of the judge. Exact punishments would also be most intimidating; therefore, a criminal code should be precise and clear. Parallel scales of crimes and punishments should be devised, and the degree of the offender's injury to society should determine the severity of his punishment. ${ }^{5}$

The impact of these ideas to which Becarria gave such a felicitous expression soon became apparent in the various reforms of the penal law which were made in the late eighteenth and the early nineteenth century in most countries. From the point of view of political philosophy, this was a victory for the demands of democracy, for the equality of all persons before the law, and for the principle of legality. From the point of view of penology, it meant the shift from capital and corporal punishments and torture, which were looked upon as instrumentalities of a feudal age, to punishments consisting of the deprivation of liberty and, therefore, more fitting for persons who had by their crimes forfeited their right to enjoy the privilege of freedom. The simple hedonistic philosophy by which Beccaria explained human motivation-and which Jeremy Bentham later was to make the foundation for his penal system-no doubt could have provided him with a basis for constructing a system requiring the individualization of punishment, but the intellectual climate of his day was not favorable. Dominated by the emerging political philosophy, he arrived at the antithesis of individualization-namely, equal punishments for equal crimes, the nature of the crime being the measure of the injury done by a criminal to society.

There is little need for stressing the fact that the penal philosophy embraced by the egalitarians and the correctional or treatment philosophy derived from the behavioral scientists are mutually incompatible. We have already noted the effect of the behavioral sciences on the penal system. A corollary effect may be noted in the administration of justice. With the increase of the number and variety of possible dispositions available to the courts, the arbitrary power of courts, which the egalitarians were desirous of destroying because of their mistrust of these agencies, has increased, and more and more discretionary power has been transferred to agencies of correctional administration.

'Cesare Bonesana Beccaria, Dei Delitti e delle Pene par. 2 (1764). 


\section{VI}

\section{Conclusion}

The history of penal legislation during the last century has been one of compromise. The treatment philosophy has constantly made more inroads, but has now reached the point of diminishing returns, one might say. The hard core of the older philosophy which demands a life for a life or at least life imprisonment for a life and a considerable degree of proportionality between the seriousness of the crime and the severity of the punishment still remains strong, however. 